\title{
The Role of Pre-Operative Intravenous Urography in Preventing Urinary Tract Injury for Benign Pelvic Lesion
}

\author{
Shyama Prasad Saha ${ }^{1 *}$, Goutam Mukherjee ${ }^{1}$, Anuradha De ${ }^{2}$, Shyamapada Pati $^{3}$ and Tapan Lahiri ${ }^{4}$ \\ ${ }^{1}$ Department of Obstetrics \& Gynaecology, North Bengal Medical College, India \\ ${ }^{2}$ Department of Pathology, RG Kar Medical College, India \\ ${ }^{3}$ Department of Obstetrics \& Gynaecology, National Medical College, India \\ ${ }^{4}$ Department of Obstetrics \& Gynaecology, Institute of Postgraduate Medical Education and \& Research, India
}

Submission: November 25, 2016; Published: February 03, 2017

*Corresponding author: Shyama Prasad Saha, B-3 Hospital Quarter, North Bengal Medical College, Sushrutanagar, Darjeeling, West Bengal, India, Pin: 734012; Tel: +919434142645; Email: drsps94@gmail.com/drsps_94@yahoo.com

\begin{abstract}
Due to close anatomical proximity of female urinary and genital tract, the ureter, urinary bladder and urethra are vulnerable for injury during gynaecological surgery. In a comparative observational study we evaluated 89cases having benign and clinically high risk gynaecological conditions requiring surgery, for the incidence of urinary tract involvement and to determine whether pre-operative assessment of urinary tract by IVU diminishes the risk of operative injury. At what circumstances IVU will be justifiable is also evaluated. In our study IVU could detect urinary tract involvement in $41.37 \%$ cases preoperatively in selected benign gynaecological condition. In the study group 2 patients sustained intraoperative urinary tract injury whereas 5 cases in control group had the same.
\end{abstract}

It is evident from our study that IVU can detect urinary tract anomaly in large number of patients in comparison to control group; the information available to gynecologist allow him/her to take steps to either prevent or detect ureteric injury during operation.

Keywords: Intravenous urography; Benign; Pelvic lesion; Pre-operative

\section{Introduction}

The urinary and genital system develop from a common intermediate mesodermal ridge; therefore the anatomical proximity of female urinary and genital tract make the ureter, urinary bladder and urethra vulnerable to injury during gynaecological surgery.

Ureteric injury is one of the most serious complications during major gynaecological and pelvic surgery; the incidence varying from $0.4-2.5 \%$ for benign condition Drake \& Nobel [1]. Obstetric and gynecological surgeries account for approximately $50 \%$ of ureteric injuries Fry et al. [2] Apart from surgical trauma either from difficult surgery or careless surgery, urinary tract is much more liable to be injured with endometriosis, enlarged pelvic tumour, previous pelvic surgery, pelvic adhesion, pelvic inflammatory disease, distorted pelvic anatomy, advanced malignancy, previous radiation Harkki-Siren [3]. Carley et al. [4] reported that the incidence of bladder and ureteric injuries were $0.58 \%$ and $0 \%$ for vaginal hysterectomy respectively and the same was $5.13 \%$ and $1.71 \%$ respectively for obstetric hysterectomy Carley et al. [4].

The pelvic surgeon should have a thorough knowledge and complete familiarity with normal pelvic anatomy. The pelvic pathology must be evaluated by clinical examination and supportive imaging as a preliminary step before any pelvic surgery. The decision to obtain a routine intravenous urogram (IVU) for evaluation of course of ureter before hysterectomy for non-malignant conditions has not been proven till date. No such randomized trial has been conducted till date to prove its application.

\section{Aim and Objective}

The aims and objectives of this study were directed to evaluate:

a. The involvement of urinary tract in benign and clinically high risk gynaecological conditions requiring surgery. 
b. Whether pre-operative assessment of urinary tract by IVU diminishes the risk of operative injury.

c. At what circumstances IVU will be justifiable.

\section{Material and Methods}

\section{Settings}

This study was conducted at North Bengal Medical College, Darjeeling and I. P.G.M.E.R , Kolkata over a period of three years from 1st June, 2007 to 31st May, 2010.

\section{Design}

This was a comparative observational study.

\section{Population}

The subjects of the study were selected from gynaecological outpatient department of those institutes mentioned above.

A group of 89 women with different benign gynecological conditions requiring surgery who underwent IVU were selected for study group.

Inclusion criteria for this study were as follows:

a. Abdominal mass corresponding with $\geq 14$ weeks size of pregnant uterus

b. Adnexal mass along with pain radiating from loin to groin.

c. Acute retention of urine with pelvi-abdominal mass.

d. All cases of uterine procedentia.

e. Pelvic retroperitoneal mass requiring surgery

f. Gynecological lesion associated with urinary tract abnormality detected incidentally by USG or CT scan.

g. Exclusion criteria were impaired renal function test and hypersensitivity to iodine containing dye and suspected malignant lesions.
A cohort of similar number of patients having similar demographic profile and same inclusion criteria were selected for control group for whom IVU was not performed. History taking, clinical examination, pre operative evaluation and workup were planned. Information regarding age, marital status, fertility and parity were also noted. USG whole abdomen was performed in patients of both groups. CT scan of abdomen was also done where situation demanded. All subjects underwent urinary analysis and renal function assessment. Preoperative IVU findings (in study group) were documented properly. DTPA (Diethylene Triamine Pentacaetic Acid) scan was performed for cases of non functioning kidney detected by IVU. A comprehensive approach for the gynecological and urological surgery was undertaken in consultation with urological surgeon. The site and type of ureteric injuries recognized at operation for both group were recorded.

Intra-operative, post operative findings and complications in relation to urinary tract were recorded for both groups and compared. Primary outcome measure in this study was incidence of urinary tract involvement in benign gynaecological conditions. Secondary outcome measures were incidence of intra-operative and post- operative urinary tract injuries of both groups and to observe whether pre-operative IVU could reduce such complication.

Two patients in study group and three patients in control group later on were found to be suffering from malignant conditions and excluded from result analysis. So 87 in study group and 86 in control group were evaluated and analysed.

\section{Statistical analysis}

The data were analysed using Medical Statistical Software Statistical analysis included Chi-square test and' $t$ ' test to compare the outcomes between the study group and the control group. A p-value less than 0.05 were considered as statistically significant.

\section{Results}

Table 1: Age, Parity and Mode of admission.

\begin{tabular}{|c|c|c|c|}
\hline Characteristic & Control Group(N=87) & Study Group $(\mathrm{N}=86)$ & $P$ Value \\
\hline \multicolumn{4}{|c|}{ Age } \\
\hline Below 20 years & $6(6.89 \%)$ & $5(5.81 \%)$ & 0.9836 \\
\hline 21-25 years & $16(18.39 \%)$ & $18(20.93 \%)$ & 0.8188 \\
\hline 26-35 years & $21(24.14 \%)$ & $19(22.09 \%)$ & 0.8891 \\
\hline $36-45$ years & $17(19.54 \%)$ & $16(18.60 \%)$ & 0.9711 \\
\hline $46-55$ years & $13(14.94 \%)$ & $15(17.44 \%)$ & 0.8104 \\
\hline $56-65$ years & $14(16.09 \%)$ & $13(15.12 \%)$ & 0.9731 \\
\hline \multicolumn{4}{|c|}{ Parity } \\
\hline P0 & $11(12.64 \%)$ & $10(11.63 \%)$ & 0.9765 \\
\hline P1 & $13(14.94 \%)$ & $12(13.95 \%)$ & 0.9752 \\
\hline P2 & $16(18.39 \%)$ & $18(20.93 \%)$ & 0.8188 \\
\hline
\end{tabular}




\section{Journal of Gynecology and Women's Health}

\begin{tabular}{|c|c|c|c|}
\hline$\geq P 3$ & $28(32.18 \%)$ & $25(29.07 \%)$ & 0.7804 \\
\hline Unmarried & $19(21.84 \%)$ & $21(24.42 \%)$ & 0.8242 \\
\hline \multicolumn{2}{|c|}{ Admitted Through } \\
\hline OPD & $51(58.62 \%)$ & $53(61.63 \%)$ & 0.8034 \\
\hline Emergency & $23(26.44 \%)$ & $21(24.42 \%)$ & 0.8962 \\
\hline Referred from other Dept & $13(14.94 \%)$ & $12(13.95 \%)$ & 0.9752 \\
\hline
\end{tabular}

Table 2: Distribution of cases.

\begin{tabular}{|c|c|c|c|}
\hline Nature of Pathology & Control Group(N=87) & Study Group(N=86) & P Value \\
\hline Fibroid & $32(36.78 \%)$ & $34(39.53 \%)$ & 0.8292 \\
\hline Endometriosis & $17(19.54 \%)$ & $16(18.60 \%)$ & 0.9711 \\
\hline Broad ligament cyst & $13(14.94 \%)$ & $11(12.79 \%)$ & 0.85 \\
\hline Procedentia & $18(20.69 \%)$ & $15(17.44 \%)$ & 0.726 \\
\hline Chronic PID & $04(4.60 \%)$ & $05(5.81 \%)$ & 0.9873 \\
\hline Ovarian neoplasm & $02(2.29 \%)$ & $02(2.33 \%)$ & 0.9862 \\
\hline $\begin{array}{c}\text { Adenomyosis with lower } \\
\text { abdominal mass }\end{array}$ & $01(1.15 \%)$ & 0.9904 \\
\hline
\end{tabular}

Table 3: Urinary tract abnormalities detected at IVU.

\begin{tabular}{|c|c|c|c|c|c|c|c|c|c|c|c|c|}
\hline \multirow[t]{2}{*}{ Diagnosis } & \multicolumn{2}{|c|}{$\begin{array}{c}\text { Ureter } \\
\text { Compressed }\end{array}$} & \multicolumn{2}{|c|}{$\begin{array}{l}\text { Ureter } \\
\text { Displaced }\end{array}$} & \multicolumn{2}{|c|}{ Hydro ureter } & \multicolumn{2}{|c|}{$\begin{array}{c}\text { Hydro } \\
\text { nephrosis }\end{array}$} & \multicolumn{2}{|c|}{$\begin{array}{l}\text { Ureteric } \\
\text { Stricture }\end{array}$} & \multirow{2}{*}{$\begin{array}{c}\text { Ureteric } \\
\text { Involvement } \\
\begin{array}{c}\text { No.of cases \& } \\
\text { percentage }\end{array}\end{array}$} & \multirow[t]{2}{*}{$\begin{array}{l}\text { Other } \\
\text { findings }\end{array}$} \\
\hline & One & Both & One & Both & Unilat & Bilat & Unilat & Bilat & Unilat & Bilat & & \\
\hline Fibroid(n=32) & & & & & & & & & & & $11(34.37 \%)$ & \\
\hline Intramural $(n=6)$ & 2 & & 2 & & & & & & & & & \\
\hline Broad ligament $(\mathrm{n}=8)$ & 2 & & 2 & & & & & & & & & \\
\hline Cervical (n=4) & 1 & & & 1 & & & & & & & & \\
\hline \multicolumn{13}{|l|}{ Subserous $(\mathrm{n}=8)$} \\
\hline Endometriosis $(n=17)$ & & & & & & & & & & & $9(52.94 \%)$ & \\
\hline \multicolumn{13}{|l|}{$\begin{array}{l}\text { Endometrioma } \\
\qquad(n=14)\end{array}$} \\
\hline Bilateral $(n=9)$ & & & & & 2 & & 1 & 1 & & & & \\
\hline Unilateral $(n=5)$ & & & & & 2 & & & & & & & \\
\hline Ureteric $(n=3)$ & & & & & & & & & 3 & & & \\
\hline $\begin{array}{l}\text { Broadligament cyst } \\
\qquad(\mathrm{n}=13)\end{array}$ & 2 & 1 & 3 & & & & & & & & $6(46.15 \%)$ & \\
\hline Procedentia $(n=18)$ & & & & & 1 & 3 & 1 & 1 & & & $6(33.33 \%)$ & \\
\hline Chronic PID (n=4) & & & & & 1 & & 1 & & & & $2(50 \%)$ & \\
\hline $\begin{array}{l}\text { Ovarian neoplasm } \\
\qquad(\mathrm{n}=2)\end{array}$ & 1 & 1 & & & & & & & & & $2(50 \%)$ & \\
\hline $\begin{array}{l}\text { Adenomyasis with } \\
\text { mass in lower } \\
\text { abdomen }(\mathrm{n}=1)\end{array}$ & & & & & & & & & & & 1 & $\begin{array}{l}\text { Horse shoe } \\
\text { shaped } \\
\text { kidney }\end{array}$ \\
\hline $\begin{array}{l}\text { Uterine fibroid with } \\
\text { renal colic }(n=32)\end{array}$ & & & & & & & & & & & 2 & $\begin{array}{l}\text { Ureteic } \\
\text { stone }\end{array}$ \\
\hline
\end{tabular}


Patients in both groups were comparable in relation to age distribution, marital status, parity and mode of admission (Table 1). Table 2 shows distribution of cases in both groups which are also comparable. Table 3 showed the diagnosis and urinary tract abnormalities by IVU in the study group. Out of 87 cases, IVU could detect urinary tract involvement in $41.3 \%$ case. Two patients with uterine fibroid had renal colic and detected to have calculus in ureter, whereas one case of horse- shoe shaped Table 4: Surgical treatment undertaken. kidney was seen by IVU in a patient of adenomyosis.

Table 4 depicted the different surgeries performed in both groups which were comparable. Intra-operative and postoperative urinary tract injury had been shown in Table $5 \& 6$ respectively. In the study group only two patients had intraoperative ureteric injuries whereas in control group five patients sustained ureteric injury.

\begin{tabular}{|c|c|c|c|}
\hline Name of Operation & Study Group (N=87) & Control Group (N=86) & P Value \\
\hline Myomectoy & $13(14.94 \%)$ & $10(11.63 \%)$ & 0.6765 \\
\hline Abdominal hysterectomy & $12(13.79 \%)$ & $11(12.79 \%)$ & 0.9759 \\
\hline Abdominial hysterectomy with bilateral salpingo-oophorectomy & $23(26.44 \%)$ & $24(27.91 \%)$ & 0.9630 \\
\hline Removal of endomerioma & $9(10.34 \%)$ & $10(11.63 \%)$ & 0.9775 \\
\hline Removal of broad ligament cyst & $8(9.19 \%)$ & $9(10.46 \%)$ & 0.8951 \\
\hline Vaginal hysterectomy & $18(20.69 \%)$ & $19(22.09 \%)$ & 0.9688 \\
\hline Ureteral resection \& uretero-neo cystotomy & $3(3.45 \%)$ & $1(1.16 \%)$ & 0.6197 \\
\hline Salphingo -oophorectomy & $1(1.15 \%)$ & $2(2.33 \%)$ & 0.9904 \\
\hline
\end{tabular}

Table 5: Intraoperative urinary tract injuries.

\begin{tabular}{|c|c|c|c|c|}
\hline Type of Injuries & Study Group (N=87) & Control Group (N=86) & P Value & Methods of Repair \\
\hline Contusion & $1(1.15 \%)$ & $2(2.33 \%)$ & 0.9904 & Conservative \\
\hline Inclusion in ligature & 0 & $1(1.16 \%)$ & 0.9973 & Excision and end to end anastomosis \\
\hline Crushing & $1(1.15 \%)$ & $2(2.33 \%)$ & 0.9904 & Ureteroneocystostomy \\
\hline Division & 0 & 0 & - & - \\
\hline
\end{tabular}

Table 6: Urinary tract injuries detected at convalescence phase.

\begin{tabular}{|c|c|c|c|c|c|}
\hline Type of Injuries & Study Group (N=87) & $\begin{array}{c}\text { Control Group } \\
\text { (N=86) }\end{array}$ & P Value & Presentation & Management \\
\hline Division & 0 & $1(1.16 \%)$ & 0.9973 & $\begin{array}{c}\text { Urinoma collection } \\
\text { urinoma, then } \\
\text { ureteroneocystostomy } \\
\text { later }\end{array}$ \\
\hline Ligation of ureter & 0 & $1(1.16 \%)$ & 0.9973 & $\begin{array}{c}\text { Pain in } \\
\text { loinHydroureter of } \\
\text { left side }\end{array}$ & $\begin{array}{c}\text { Ureteroneocystotomy } \\
\text { later }\end{array}$ \\
\hline
\end{tabular}

\section{Discussion}

Several studies have defined the prevalence of abnormal preoperative IVU in gynaecological conditions. Roden et al. [5] noted $15.3 \%$ genitourinary anomalies in 455 patient undergoing major pelvic surgeries Roden et al. [5]. Schartz et al. [6] found $13.4 \%$ prevalence of genitourinary involvement in their study Schartz et al. [7]. 14.2\% prevalence of genitourinary abnormality was reported for all type of gynaecological surgery by Klissaristos et al. [8] whereas Piscitelli et al. [10] in retrospective review found $27 \%$ abnormal finding in pre-operative IVU Klissaristos et al. [8]; Piscitelli et al. [10]. Our finding was $41.37 \%$ in study group and was higher; this might be due to inclusion of selected cases like pelvic mass more than 14 weeks and referred cases and also routine IVU was not used as a diagnostic tool.
Large intramural leiomyoma occupying above the pelvis, broad ligament fibroid and cervical fibroid had caused compression and displacement of ureter in $34.37 \%$ in our study. In a retrospective study at Duke university medical center the authors reported $20 \%$ prevalence of ureteral dilatation and $10 \%$ of ureteral deviation by uterine size 12 weeks or larger. Larger fibroid above pelvic brim causing obstruction had been disputed in a study which showed only significant obstruction in only 9 cases out of 598 patients with fibroid of all sizes Buchsbaum \& Schmidt [11]. Ureteral obstruction by extrinsic compression is reported by large pelvic tumour most commonly leiomyoma Thompson [12]. Intra-ligamentary fibroid is relatively fixed and because of their position can cause ureteral displacement and obstruction Barnik \& Cardizo [13]. Once the pelvic mass has 
been removed the radiography changes rapidly revert to normal Barnik \& Cardizo [13].Our study conform to these studies.

Marked dilatation of ureter and hydronephrosis had been reported when complete uterine procidentia had been chronic over many years. We had noted hydroureter and hydronephrosis in $33.33 \%$ of patient in our study group; most of them were long standing for five years or more. Rudin et al. [14] studied 95 patients with uterine prolapse and found 7\% prevalence of hydroureteronephrosis Rudin et al. [14]. Jones and Evison reported a huge $66 \%$ prevalence of ureteral dilatation in patient with sever procidentia Jones \& Evison [15]. Third degree prolapse with 17 $\%$ hydroureter was noted in a study at Duke University medical center Piscitelli et al. [10] The prevalence of mild, moderate and severe hydronephrosis with pelvic organ prolapse were detected in $4 \%, 2.8 \%$ and $0.9 \%$ of subjects respectively by Baverly et al in a study of 375 patient of genitor urinary prolapse Beverley et al. [16]. The obstruction is usually relieved by surgical correction Thompson [17]. The true incidence of urinary complication with endometriosis is neither known nor all sufferers were fully urologically investigated. We observed $34 \%$ of the patients of ovarian endometriosis had ureteric dilatation and hydronephrosis. Thomson and Schroder suggested that it is important to consider urinary tract involvement in all cases of severe endometriosis Thomson \& Schroder [12]. To date over 100 cases of ureteral involvement by endometriosis had been reported. About 25\% kidney are lost when endometriosis obstruct the ureter Moore et al. [18]. Prevalence of 18\% ureteral dilatation patients was reported out of 16 patients Piscitelli et al. [10]. It is recommended that routine IVU or ultrasound follow up after treatment of endometriosis is required Miller \& Morgan [19]. In extrinsic involvement the ureter becomes compressed by endometriosis originating at broad ligament or ovary. In intrinsic involvement the endometriotic implant arises within ureteric wall and some portion of ureter has to be resected Barnik \& Cardizo [13]. In our study three such cases were observed and ureteroneocystostomy was done in the study group.

Chronic Pelvic inflammatory disease with adenexal mass had caused hydroureter and hydronephrosis in 2 out of 4 cases in our study group. In one study preoperative IVU in 44 patients with tubo-ovarian abscess, ureteral dilatation \& deviation were observed in 30\% and 36\% patients respectively (Phillips, 1974). In another similar study, out of 34 patients of PID with adenexal mass, 21\% had ureteral dilatation and $9 \%$ had deviation Piscitelli et al. [10]. In our series out of 4 cases of PID, two had hydroureter.

Large ovarian neoplasm, can cause pressure effect on the ureter leading to obstruction, as they tend to be cystic and mould to the contour of the pelvis Barnik \& Cardizo [13]. The incidence of benign tumour causing ureteral obstruction was $57.8 \%$ in the same study. We noted in two patients of ovarian tumour had caused ureteric compression in our study.

In our study group two patients had intra-operative ureteric injury of which one had contusion of ureter in a case of central cervical fibroid and another had crushing injury in a case of pelvic inflammatory disease with tubo-ovarian mass. They were managed conservatively and by uretero neocystotomy respectively. There was no unrecognized urinary injury in this group during operation. In the control group a total of five cases had different types of ureteric injuries during operation which include contusion, inclusion in a ligature and crushing injury. In two cases of huge broad ligament cyst we had crushing injuries of ureter which were managed conservatively. Ureter was included in the ligature in a case of central cervical fibroid which was detected during the operation and treated by excision and end to end anastomosis. In two cases of bilateral endometrioma of ovary with gross pelvic adhesion, ureter of left side were crushed and managed by uretero neocystostomy.

Ureteric injuries were recognized during convalescence in two patients of control group but none in the study group. In a case of severe pelvic inflammatory disease with tuboovarian mass, ureter was devided in its lower part and patient developed urinoma which was managed by drainage of urinoma and later by ureteroneocystostomy. In another case of severe endometriosis, left ureter was involved in the ligature and ureteroneoureterostomy was performed later.

Numerous studies reported the frequency of ureteric injury related to hysterectomy. Not a single study conclusively stated whether a preoperative IVU reduces the risk of injury. To evaluate the role of pre-opeartive IVU in preventing preoperative ureteric injury, Seek compared a group of 70 patients undergoing abdominal hysterectomy with pre-operative IVU with a group of 260 patients without pre-opertive IVU Seek, [20]. The author concluded that he had failed to prove that pre-operative IVU helped to prevent urinary tract injury during abdominal hysterectomy as there was one ureteral injury identified in non IVU group.

The study of Piscitelli et al. was limited by small sample size and methodologically retrospective Piscitelli et al. [10]. But in a different study 22 the authors pointed out that routine pre-operative IVU was not cost effective, as 833 patients had to undergo IVU to prevent a single ureteric injury Schwenzer \& Beek [6]. These authors suggested abnormal finding in clinical \& physical examinations will be taken into account for selectively perform IVU to decrease cost and adverse reaction of IVU.

\section{Conclusion}

It is evident from our study that IVU can detect urinary tract abnormality in large number of patients in comparison to control group; the information available to gynaeclogist help him/her to take steps to either prevent or detect ureteric injury during operation.

Moreover pre-operative IVU has got medico-legal importance as stated by a group of worker Schwenzer \& Beek [6,21]. Damage to the efferent urinary passage during abdominal or vaginal hysterectomy cannot always be prevented no matter how careful one may proceed pre-operatively and intra-operatively. However 
all possibilities of avoiding complication or at least recognizing and eliminating these before surgery, must be explored especially in high risk cases using IVU and other supportive investigations.

The effectiveness of pre-operative intravenous urography in preventing intra-operative ureteral injury will continue to remain debatable unless a large prospective randomized controlled trial is carried out.

\section{References}

1. Drake MJ, Nobel JG (1998) Ureteric trauma in gynaecologic surgery. It Urogynecol 9: 108-117.

2. Fry DE, Milnolen L, Harbrecht PJ (1983) Iatrogenic ureteral injury:options in management. Arch Surg 118(4): 454-457.

3. Harkki-Siren P, Sjoberg J, Tiitinea A (1998) Urinary tract injuries after hysterectomy. Obstet Gynecol 92(1): 113-118.

4. Carley ME, Mc Intire D, Carley JM, Schaffer J (2002) Incidence, risk factors and morbidity of unintended bladder or ureteral ijury during hysterectomy. Int urogynecol J Pelvic Floor Dysfunct 13(1): 18-21.

5. Roden JS, Hangen HM, Hall DG, Greenberg PA (1961) The value of intravenous pyelography prior to elective gynecologic operations. Am J Obstet Gynecol 82: 568-571.

6. Schwenzer T, Beek L (1992) Forensic aspects of bladder and ureteral injuries in standard gynecological operation. Artcle in German. Geburtshilfe Frauenheilkd 52: 632-37.

7. Schartz WR, Hofmeister FJ, Mattigly RF (1964) The Value of intravenous urogram in pelvic surgery. Obstet Gynecol 23(4): 584-588.

8. Klissaristos AA, Manouelides NS, Comminos AC (1974) Preoperative intravenous pyelography in gynecology. Int surg 59(1): 31-32.

9. Piscitelli JT, Simel DL, Addison WA (1987) Who should have intravenous pyelogram before hysterectomy for benign disease? Obstet Gynecol 69(4): 541-545.

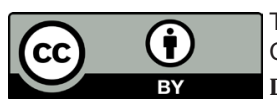

This work is licensed under Creative Commons Attribution 4.0 License

DOI: $10.19080 / J G W H .2017 .02 .555585$
10. Buchsbaum H, Schmidt J (1982) Gynaecological and Obstetric Urology, ( $2^{\text {nd }}$ edn), WB Saunders Philadelphia Chap 26, England, pp. 397.

11. Thomson H, Schroder HM (1987) Simultaneous external and internal endometriosis of ureter. Case report. Scandinavian journal of urology and nephrology.

12. Barnik CG, Cardizo LD (2000) Clinical Urogynaecology. (1 $1^{\text {st }}$ edn), Churchill Livingstone London Chap 25, England, pp. 273-286.

13. Rudin LJ, Megalli MR, Lattimer JK (1974) Obstetric uropathy associated with uterine prolapse. Urology 4: 73.

14. Jones JB, Evison G (1977) Excretion urography before and after surgical treatment of procedentia. Br J Obstet Gynaecol 84(4): 304-308.

15. Beverley CM, walters MD, Weber AM, Pied monte MR, Balland LA (1997) Prevalence of hydronephrosis in apatient undergoing surgery for pelvic organ prolapse. Obstet Gynecol 90(1): 37-41.

16. Thompson JD (1997) Operative injuries to the ureter: Prevention, Recognition and management TeLinde's Operative Gynecology. $\left(8^{\text {th }}\right.$ edn), Rock J A, Thompson J D (Eds.), Lippincott-Raven Publishers , Philadelphia-New York, England, pp. 1135-1173.

17. Moore JG, Hibbard Lt, Growder WA, Schifrin BS (1979) Urinary tract endometriosis: enigma in diagnosis and management. Trans Pac Coast Obstet Gynecol Soc 46: 61-71.

18. Miller MA, Morgan RJ (1990) Bilateral ureteric obstruction due to endrometriosis resulting in unilateral loss of renal function. Br J Urol 65(4): 421.

19. Seek RA (1979) The value of intravenous urography prior to abdominal hysterectomy for gynecological disease. Int J Obstet Gynecol 134(2): 208-212.

20. Phillips JC (1974) Spectrum of radiologic abnormalities due to tuboovarian abscess. Radiology 110(2): 307-311.

21. Simel DL, Matchar DB, Piscite I JT (1988) Routine intravenous pyelogram before hysterectomy in cases of benign disease possibly elective, definitely expensive. Am J Obstete Gynecol 159: 1049-1053.

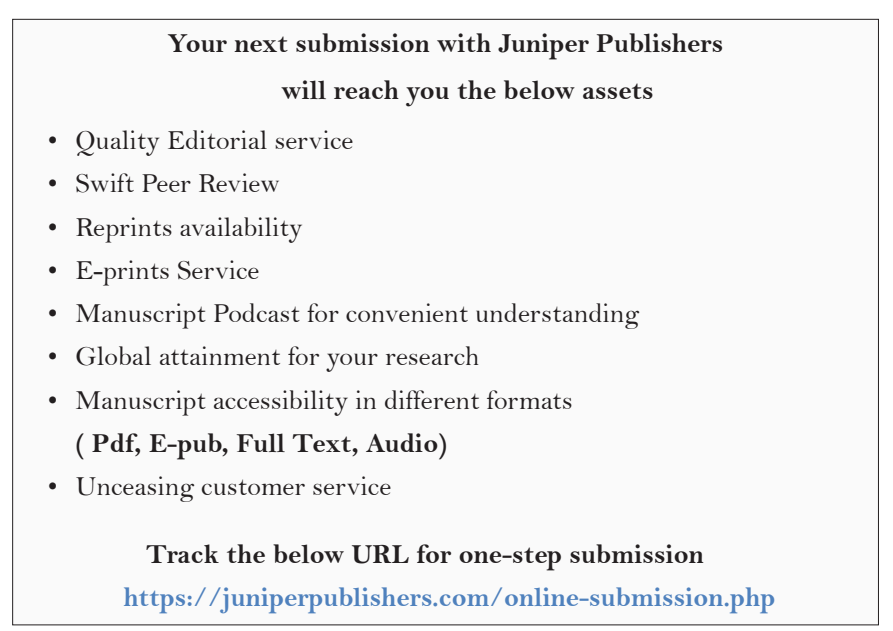

